\title{
No Separation
}

\author{
Jon Kabat-Zinn ${ }^{1}$
}

Published online: 24 April 2018

(C) Jon Kabat-Zinn 2018

Einstein, who in his time saw more deeply than others into the nature of space and time, matter and energy, light and gravitation, also saw, perhaps equally deeply, into the blinding effects of desire and attachment and how important it is to dissolve what he called the delusion of separateness. Responding to a rabbi who had written him seeking advice for how to explain the death of his daughter, a "sinless, beautiful sixteen-year-old girl," to her older sister, Einstein replied:

A human being is a part of the whole, called by us "Universe," a part limited in time and space. He experiences himself, his thoughts and feelings as something separated from the rest - a kind of optical delusion of his consciousness. This delusion is a kind of prison for us, restricting us to our personal desires and to affection for a few persons nearest to us. Our task must be to free ourselves from this prison by widening our circle of compassion to embrace all living creatures and the whole nature in its beauty. Nobody is able to achieve this completely, but the striving for such achievement is in itself a part of the liberation, and a foundation for inner security.

That Einstein, a great physicist, is speaking of liberation and inner security is in itself hugely telling. It underscores how much he felt we are all plagued by the delusion of separation, the separation of me from myself, and me from you, and I from Thou, how much he understood the suffering that stems from it, and the need to guard against it by cultivating compassion.

Excerpted from the book Coming To Our Senses: Healing Ourselves and the World Through Mindfulness by Jon Kabat-Zinn. Copyright (C) 2005 Jon Kabat-Zinn, Ph.D. Published by Hachette Books. All Rights Reserved.

Jon Kabat-Zinn

mindfulness@umassmed.edu

1 Center for Mindfulness, University of Massachusetts Medical School, 55 Lake Avenue North, Worcester, MA 01655, USA
He saw in terms of wholes, with eyes of wholeness. And in terms of liberation from delusion. And his response was . . compassion.

Can we ask ourselves to see with eyes of wholeness as well, and be aware of the prisons we create for ourselves and for others through our delusions of separation when fundamentally there really is none? Can we, as Einstein put it, widen our circle of compassion to "embrace all living creatures and the whole nature in its beauty"? And can we include ourselves in that circle of compassion?

Why not?

It is a practice, after all, not a philosophy. And that practice is called waking up from the delusions, the fragmentations, the abdications, the fabrications of our own mis-perceptions; it is called freeing ourselves from what appears to be "apartness" when in fact, at the deepest of levels, we truly belong, have always been seamlessly woven into the whole, are already at home, here, in this moment, with this breath, in this place.

\author{
Ah, not to be cut off, \\ not through the slightest partition \\ shut out from the law of the stars. \\ The inner-what is it? \\ if not intensified sky, \\ hurled through with birds and deep \\ with the winds of homecoming. \\ Rilke \\ Translated by Stephen Mitchell
}

